九州大学学術情報リポジトリ

Kyushu University Institutional Repository

\title{
Intracerebroventricular injection of $\mathrm{L}$-proline and D-proline induces sedative and hypnotic effects by different mechanisms under an acute stressful condition in chicks
}

Hamasu, Kousuke

Laboratory of Advanced Animal and Marine Bioresources, Graduate School of Bioresource and Bioenvironmental Sciences, Kyushu University

Shigemi, Kazutaka

Laboratory of Advanced Animal and Marine Bioresources, Graduate School of Bioresource and Bioenvironmental Sciences, Kyushu University

Tsuneyoshi, Yousuke

Laboratory of Advanced Animal and Marine Bioresources, Graduate School of Bioresource and Bioenvironmental Sciences, Kyushu University

Yamane, Haruka

Laboratory of Advanced Animal and Marine Bioresources, Graduate School of Bioresource and Bioenvironmental Sciences, Kyushu University

他

http://hdl. hand le. net/2324/26477

出版情報：Amino Acids. 38 (1)，pp.57-64，2010-01. Springer Verlag バージョン：

権利関係: (C) Springer-Verlag 2008 


\section{Intracerebroventricular injection of $L$-proline and D-proline induces sedative and hypnotic effects by different mechanisms under an acute stressful condition in chicks}

K. Hamasu ${ }^{1}$, K. Shigemi ${ }^{1}$, Y. Tsuneyoshi ${ }^{1}$, H. Yamane $^{1}$, H. Sato ${ }^{2}$, D.M. Denbow ${ }^{3}$, and M. Furuse ${ }^{1, *}$

${ }^{1}$ Laboratory of Advanced Animal and Marine Bioresources, Graduate School of Bioresource and Bioenvironmental Sciences, Kyushu University, Fukuoka 812-8581, Japan

${ }^{2}$ Ajinomoto Co., Inc, Kawasaki-ku, Kawasaki-shi 210-8681, Japan

${ }^{3}$ Department of Animal and Poultry Sciences, Virginia Polytechnic Institute and State University, Blacksburg, VA 24061-0306, USA

Correspondence should be addressed to M. Furuse, Graduate School of Bioresource and Bioenvironmental Sciences, Kyushu University, Fukuoka 812-8581, Japan

TEL: (81) (92)642-2953

FAX: (81) (92)642-2953

E-mail: furuse@brs.kyushu-u.ac.jp 


\begin{abstract}
The central effects of L-proline, D-proline and trans-4-hydroxy-L-proline were investigated by using the acute stressful model with neonatal chicks in Experiment 1 . Sedative and hypnotic effects were induced by all compounds, while plasma corticosterone release under isolation stress was only attenuated by L-proline. To clarify the mechanism by which L-proline and D-proline induce sedative and hypnotic effects, the contribution of the strychnine-sensitive glycine receptor (glycine receptor) and $N$-methyl-D-aspartate glutamate receptor (NMDA receptor) were further investigated. In Experiments 2-3, the glycine receptor antagonist strychnine was co-injected intracerebroventricular (i.c.v.) with L-proline or D-proline. The suppression of isolation-induced stress behavior by D-proline was attenuated by strychnine. However, the suppression of stress behavior by L-proline was not attenuated. In Experiment 4, the NMDA receptor antagonist (+)-MK-801 was co-injected i.c.v. with L-proline. The suppression of stress behavior by L-proline was attenuated by (+)-MK-801. These results indicate that L-proline and D-proline differentially induce sedative and hypnotic effects through NMDA and glycine receptors, respectively.
\end{abstract}

Keywords: CNS, stress, strychnine, (+)-MK-801, strychnine-sensitive glycine receptor, NMDA receptor 


\section{Introduction}

There are many studies suggesting that L-proline may be a neuronal modulator or transmitter candidate in the central nervous system (CNS) (Snyder et al. 1973; Yoneda and Roberts 1982; Fremeau et al. 1992; Renick et al. 1999; Gogos et al. 1999). We have previously demonstrated that the amount of L-proline in the brain was reduced under stressful conditions, and intracerebroventricular (i.c.v.) injection of L-proline had sedative and hypnotic effects under an acute stressful condition in neonatal chicks (Hamasu et al. 2009). From these facts, it appears that L-proline might function through several neurotransmitter systems in the CNS. However, the mechanism by which L-proline attenuates stress behavior is presently unknown.

The behavioral model is based on the response of neonatal chicks to acute stress (Panksepp et al. 1980; Sahley et al. 1981; Feltenstein et al. 2003a, b). In brief, chicks grown in crowds feel acute stress when they are isolated. This isolation-induced stress increases vocalization and plasma corticosterone concentration. This isolation-induced stress paradigm has been used as an objective model for anxiolytic drug screening, with vocalization and plasma corticosterone concentration as the index of the behaviors induced by the stressor.

L-Proline is an amino acid. However, it differs from other amino acids in that it has imino group and its side chain is bound to both nitrogen and $\alpha$-carbon atoms. L-Pipecolic acid has the molecular structure that looks like L-proline very well. Takagi et al. (2001) demonstrated that i.c.v. injection of L-pipecolic acid induced sleep-like behavior in neonatal chicks. From these findings, it is suggested that these molecular structures are important in inducing sedative and hypnotic effects.

The purpose of the present study was 1) to confirm the effect of L-proline and proline-related compounds such as D-proline and trans-4-hydroxy-L-proline under the acute stressful model in neonatal chicks (Experiment 1), and 2) to 
determine which receptors mediate the actions of these compounds (Experiments 2-4).

The strychnine-sensitive glycine receptor (glycine receptor) is a pentameric ligand-gated anion channel composed of two different subunits, $\alpha$ and $\beta$. Also the $N$-methyl-D-aspartate glutamate receptor (NMDA receptor) is an excitatory amino acid ligand-gated ion channel that is selectively activated by NMDA and regulated at several pharmacologically distinct sites. This receptor is present in both the hypothalamus (Halpain et al. 1984) and pituitary (Lindstrom and Ohlsson 1992), suggesting its role in neuroendocrine regulation (Mahesh et al. 1999). Past studies showed that although L- and D-proline can activate the glycine receptor, the NMDA receptor is activated by L-proline alone (Henzi et al. 1992; Ortiz et al. 1996). In addition, glycine (Asechi et al. 2006) and L-glutamate (Yamane et al., unpublished data) caused a sedative and hypnotic effect similar to that observed with L-proline. So, we hypothesized that these receptors are involved in the action of proline to induce sedative and hypnotic effects which was investigated using the glycine receptor antagonist strychnine and NMDA receptor antagonist (+)-MK-801.

\section{Material and methods}

\section{Animals and food}

One-day-old male layer chicks (Julia) purchased from a local hatchery (Murata Hatchery, Fukuoka, Japan) were maintained in a windowless room at a constant temperature of $30 \pm 1^{\circ} \mathrm{C}$. Lighting was provided continuously for $24 \mathrm{~h}$. Chicks were given free access to a commercial starter diet (Toyohashi Feed and Mills Co. Ltd, Aichi, Japan) and water. On the experimental day, chicks (4- or 5-day-old) were distributed into groups based on their body weight, so that the average body weight was as uniform as possible within the same experiment. Experimental procedures followed the guidance for Animal Experiments in the 
Faculty of Agriculture and in the Graduate Course of Kyushu University and the Law (No. 105) and Notification (No. 6) of the Japanese Government. The number of animals used and their discomfort were minimized.

\section{Preparation of drugs}

L-Proline and trans-4-hydroxy-L-proline were a gift from Kyowa Hakko Kogyo (Tokyo, Japan). The D-proline and glycine receptor antagonist strychnine and the NMDA receptor antagonist (+)-MK-801 maleate were purchased from Sigma (St. Louis, MO) and Tocris Bioscience (Ellisville, USA), respectively. In Experiments 1 and 4, L-proline, D-proline, trans-4-hydroxy-L-proline, and (+)-MK-801 were dissolved in $0.85 \%$ saline containing $0.1 \%$ Evans Blue solution. In Experiments 2 and 3, strychnine was dissolved in $0.85 \%$ saline containing 5\% dimethyl sulfoxide (DMSO) and $0.1 \%$ Evans Blue solution. L-Proline and D-proline were treated similarly.

\section{Intracerebroventricular (i.c.v.) injection and behavioral observation}

In all experiments, drugs were injected into the left lateral ventricle of the chicks using a microsyringe according to the method of Davis et al. (1979) and Koutoku et al. (2005). The stress and discomfort by this method is minimal as described elsewhere (Koutoku et al. 2005).

After the injection, chicks were placed in an acrylic glass monitoring cage $(40 \mathrm{~cm} \times 30 \mathrm{~cm} \times 20 \mathrm{~cm})$ with paper on the floor, and behavioral observations were made for $10 \mathrm{~min}$ at a constant temperature of $30 \pm 1^{\circ} \mathrm{C}$. The monitoring systems were set in a separate room to avoid disturbing the animals. The number of distress vocalizations, which are shrill and intense calls, was simultaneously recorded and counted, using a computer with Gretchen software (Excla Inc., Japan). Chicks were recorded by three video cameras positioned in different directions. Based on the method by van Luijtelaar et al. (1987), the behaviors were classified into four categories: (1) active wakefulness; (2) standing/sitting motionless with eyes opened; (3) standing 
motionless with eyes closed; and (4) sitting motionless with head drooped (sleeping posture) by watching the videotapes. They demonstrated the correlation between sleeping posture and electrophysiological sleep with EEG measurement (van Luijtelaar et al. 1987). During the monitoring period, chicks were not given food or water. These behavioral experiments were conducted according to the methods of Takagi et al. (2001), Koutoku et al. (2005) and Asechi et al. (2006).

Experiment 1: Effects of L-proline, D-proline and trans-4-hydroxy-L-proline on the stress response under isolation-induced stress.

Chicks were given i.c.v. injections of $0.50 \mu \mathrm{mol}$ of L-proline, D-proline, trans-4-hydroxy-L-proline, or saline as the control. This dosage of L-proline was based on a previous experiment (Hamasu et al. 2008). The dosage of D-proline and trans-4-hydroxy-L-proline was same as L-proline. After the behavioral observations, blood was collected in heparinized microtubes from the jugular vein. In addition, the intact group (with neither i.c.v injection nor isolation stress) was also sampled. Blood was centrifuged at $4{ }^{\circ} \mathrm{C}$ and $10,000 \mathrm{x} \mathrm{g}$ for $4 \mathrm{~min}$, and the plasma collected and stored at $-30^{\circ} \mathrm{C}$ until analysis. Plasma corticosterone concentration was determined using a corticosterone enzyme immunoassay kit (Assay Designs Inc., MI, USA.).

Experiment 2: Effects of strychnine on sedative and hypnotic behaviors induced by L-proline

Chicks were divided into four groups that received either saline, $2.99 \mathrm{nmol}$ of strychnine, $0.50 \mu \mathrm{mol}$ of L-proline, or strychnine plus L-proline. This dosage of strychnine was based on a previous experiment (Sigemi et al. unpublished data). After the injection, behavioral observations were conducted.

Experiment 3: Effects of strychnine on sedative and hypnotic behaviors induced by D-proline

This experiment was similar to Experiment 2 except that L-proline was 
replaced with D-proline $(0.50 \mu \mathrm{mol})$.

Experiment 4: Effects of (+)-MK-801 on sedative and hypnotic behaviors induced by L-proline

Chicks were divided into four groups that received either saline, $0.50 \mathrm{nmol}$ of (+)-MK-801, $0.50 \mu \mathrm{mol}$ of L-proline, or (+)-MK-801 plus L-proline. This dosage of (+)-MK-801 was determined in a pilot study. After injection, behavioral observations were conducted.

\section{Statistical analysis}

The chicks were decapitated after an overdose of sodium pentobarbital. The brains were removed and location of the Evans Blue dye was confirmed. Data of chicks without dye in the lateral ventricle were deleted. In Experiment 1, data were statistically analyzed by one-way analysis of variance (ANOVA). In Experiments 2-4, data were statistically analyzed by two-way ANOVA. Tukey-Kramer test was used as a post hoc test. Statistical analysis was conducted using a commercially available package StatView (version 5, SAS Institute, Cary, USA. 1998).

\section{Results}

\section{Experiment 1}

Fig. 1 shows the effect of i.c.v. injection of saline, L-proline, D-proline, trans-4-hydroxy-L-proline on distress vocalizations during the $10 \mathrm{~min}$ isolation-induced stress. Significant effects on total distress vocalizations ( $F(3$, 16)=25.347, $\mathrm{P}<0.001$ ) were detected. All drugs significantly decreased distress vocalizations compared to the control.

Fig. 2 shows the effect of i.c.v. injection of saline, L-proline, D-proline, trans-4-hydroxy-L-proline on plasma corticosterone concentration immediately after 10 min of isolation. The effect of the drugs on plasma corticosterone concentration 
was significant $(F(4,19)=5.046, \mathrm{P}<0.01)$. Only L-proline significantly lowered the corticosterone level compared to the control group, and these values were as low as that of the intact group. D-Proline and trans-4-hydroxy-L-proline had no effect on plasma corticosterone levels.

Table 1 shows the effect of i.c.v. injection of L-proline, D-proline, and trans-4-hydroxy-L-proline on various behavioral categories of chicks during the 10 min behavior observation period under isolation stress. Significant effects were observed in active wakefulness $(F(3,16)=40.296, \mathrm{P}<0.0001)$ and sleeping posture $(F(3,16)=17.850, \mathrm{P}<0.0001) . \quad$ L-Proline, D-proline, and trans-4-hydroxy-L-proline induced sedative and hypnotic effects compared with the saline control.

\section{Experiment 2}

Fig. 3 shows the effect of i.c.v. injection of L-proline with or without strychnine on distress vocalizations during the $10 \mathrm{~min}$ isolation-induced stress. A significant effect of L-proline $(F(1,19)=31.049, \mathrm{P}<0.0001)$ was detected, but no significant effect was observed with strychnine $(F(1,19)=0.046, \mathrm{P}>0.05)$. The lack of a significant $(F(1,19)=1.338, \mathrm{P}>0.05)$ interaction between L-proline and strychnine implies that the effect of L-proline could not be attenuated by strychnine.

The effect of i.c.v. injection of strychnine on behaviors induced by L-proline is shown in Table 2. Interactions between L-proline and strychnine were not significant for any category indicating that strychnine did not alter behaviors induced by L-proline.

\section{Experiment 3}

Fig. 4 shows the effect of i.c.v. injection of D-proline with or without strychnine on distress vocalizations during the $10 \mathrm{~min}$ isolation-induced stress. Significant effects of D-proline $(F(1,22)=7.256, \mathrm{P}<0.05)$ and strychnine $(F(1$, 22)=4.627, $\mathrm{P}<0.05)$ were detected. An interaction between D-proline and strychnine was nearly significant $(F(1,22)=3.482, \mathrm{P}=0.075)$ suggesting that the 
suppressive effect of D-proline on distress-induced vocalizations was moderately attenuated by co-injected of strychnine.

The effect of i.c.v. injection of strychnine on behaviors induced by D-proline is shown in Table 3. Interactions between D-proline and strychnine were significant in the following categories: active wakefulness $(F(1,22)=6.913, \mathrm{P}<0.05)$ and sitting motionless with head drooped (sleeping posture) $(F(1,22)=19.330$, $\mathrm{P}<0.001)$. D-Proline increased sitting motionless with head drooped (sleeping posture) and decreased active wakefulness, and strychnine attenuated these effects. Since strychnine did not affect the behavioral categories under the control conditions, these results indicate that strychnine altered behaviors induced by D-proline. Sleeping posture induced by D-proline was attenuated by co-injection with strychnine and consequently, the behavior of chicks tended toward wakefulness.

\section{Experiment 4}

Fig. 5 shows the effect of i.c.v. injection of L-proline with or without (+)-MK801 on distress vocalizations during the $10 \mathrm{~min}$ isolation-induced stress. Significant effects of L-proline $(F(1,26)=8.530, \mathrm{P}<0.01)$ were detected, but the effect of (+)-MK801 was not significant $(F(1,26)=1.390, \mathrm{P}>0.05)$. A significant $(F(1,26)=11.708, \mathrm{P}<0.01)$ interaction between L-proline and $(+)$-MK801 suggested that the suppressive effect of L-proline on distress-induced vocalizations was attenuated by co-injected of (+)-MK801.

The effect of i.c.v. injection of (+)-MK801 on behaviors induced by L-proline is shown in Table 4. The interactions between L-proline and (+)-MK801 were significant in the following categories: active wakefulness $(F(1,26)=19.217$, $\mathrm{P}<0.001)$, standing/sitting motionless with eyes opened $(F(1,26)=6.876, \mathrm{P}<0.05)$ and sitting motionless with head drooped (sleeping posture) $(F(1,26)=11.725, \mathrm{P}<0.01)$. These results indicate that (+)-MK801 altered behaviors induced by L-proline. Sleeping posture induced by L-proline was attenuated by co-injection with 
(+)-MK801 and consequently, the behavior of chicks tended toward wakefulness.

\section{Discussion}

In order to examine whether D-proline and trans-4-hydroxy-L-proline have sedative and hypnotic effects similar to L-proline, all drugs were centrally administered and then the behavior and plasma corticosterone concentration of neonatal chicks under isolation-induced stress were determined in Experiment 1. D-Proline and trans-4-hydroxy-L-proline as well as L-proline attenuated isolation stress-induced behaviors during the 10 min post-injection period (Fig. 1 and Table 1). However, L-proline, but not D-proline or trans-4-hydroxy-L-proline, significantly lowered plasma corticosterone level compared to the control group (Fig. 2). Therefore, L-proline might have the ability to directly suppress the secretion of corticosterone from the adrenal glands through the hypothalamic-pituitary-adrenal (HPA) axis in response to stress. On the other hand, D-proline and trans-4-hydroxy-L-proline appear not to have such an effect. As a result, the mechanism of sedative and hypnotic effects of L-proline in chicks appears different from D-proline and trans-4-hydroxy-L-proline. Therefore, the mechanism of L-proline and D-proline was examined in Experiments 2-4.

L-Proline has long been recognized as a neuronal modulator or transmitter candidate in the CNS (Snyder et al. 1973). In addition, Henzi et al. (1992) revealed that L- and D-proline can activate the glycine receptor, while L-proline alone can also activate the NMDA receptor. This suggests that these receptors might be involved in the mechanisms whereby L- and D-proline induce sedative and hypnotic effects. To examine these possibilities, the effect of co-injection of L- or D-proline with the glycine receptor antagonist strychnine on behavior of neonatal chicks under isolation-induced stress was investigated. Sedative and hypnotic effects induced by L-proline were not attenuated by co-injection of strychnine (Fig. 3 and Table 2). 
However, effects induced by D-proline were partially attenuated by strychnine (Fig. 4 and Table 3). The i.c.v. injection of 2.99 nmol of strychnine alone dose not influence isolation stress-induced behaviors (Shigemi et al. unpublished data). These results indicate that the glycine receptor is involved in sedative and hypnotic effects induced by D-proline, but not L-proline. In vitro, L-proline can activate the glycine receptor (Henzi et al. 1992; Ortiz et al. 1996). However, this receptor is not involved in the action of L-proline to induce sedative and hypnotic effects in vivo.

Previous studies reported that this receptor is playing important roles in controlling motor functions, sensory signaling in vision and audition (Lopez-Corcuera et al. 2001) and inflammatory pain sensitization (Harvey et al. 2004). However, few studies have examined its role in the stress response. Our results suggest that the glycine receptor might be involved in part of the stress response.

Secondly, the effect of co-injection of L-proline with the NMDA receptor antagonist (+)-MK-801 on behavior of neonatal chicks under isolation-induced stress was investigated. The sedative and hypnotic effects induced by L-proline were attenuated by co-injection of (+)-MK-801 (Fig. 5 and Table 4). These results indicate that the NMDA receptor is involved in sedative and hypnotic effects induced by L-proline.

The NMDA receptor is well established as playing important roles in neuroendocrine regulation (Mahesh et al. 1999). In fact, NMDA stimulates corticotrophin-releasing hormone release from rat hypothalamic slices, and this effect is inhibited by an NMDA receptor antagonist (Joanny et al. 1997). Several studies examined the role of the NMDA receptor in vivo. Systemic administration of NMDA enhanced adrenocorticotropin (ACTH) and serum corticosterone secretion (Farah et al. 1991), and the secretion of ACTH in response to immobilization stress 
was inhibited by a NMDA centrally acting receptor antagonist (Jezova et al. 1995). Thus, this receptor is involved in the regulation of the HPA axis. In our study, the increase in plasma corticosterone induced by isolation stress was suppressed with i.c.v. injections of L-proline. Presumably, this effect was mediated via the NMDA receptor activity which was modulated by L-proline.

Previous studies indicated that activation of dopaminergic and serotonergic pathways are related to behavioral and emotional changes (Abercrombie et al. 1989; Gruss et al. 1996). For example, isolation-induced stress resulted in a significant increase of 5-hydroxyindoleacetic acid and only a slight increase of homovanillic acid in the forebrain of domestic chicks (Gruss et al. 1996). Additionally, some experiments suggested a modulatory interaction between the glutamatergic and monoaminergic pathway, which is mediated via NMDA receptor activation (Gruss et al. 1999). Arco and Mora (2001) showed that local activation of prefrontal NMDA receptors reduced the stress-induced dopamine release in the prefrontal cortex of the rat. From these findings, we assumed that L-proline modulates activation of NMDA receptors and alters activation of dopaminergic and serotonergic pathways. Through this mechanism, i.c.v. injection of L-proline might induce sedative and hypnotic effects under an acute stressful condition in neonatal chicks. Indeed, i.c.v. injection of L-proline suppressed the increase in serotonin turnover rate and slightly suppressed the increase in dopamine turnover rate induced by isolation stress in the telencephalon (Hamasu et al. unpublished data). However, the effect of L-proline on the stress-induced monoamines release is still obscure. Further study is necessary to clarify this potential.

In conclusion, the i.c.v. injection of L-proline and D-proline induces sedative and hypnotic effects under an acute stressful condition in neonatal chicks. However, L-proline, but not D-proline significantly lowered plasma corticosterone level. Probably, it is attributed to difference of action mechanism. The 
mechanism of attenuation of the acute stress response by L-proline is mediated by the modulation of NMDA receptor in the CNS. On the contrary, D-proline is mediated by the modulation of glycine receptor.

\section{Acknowledgments}

This work was supported by a Grant-in-Aid for Scientific Research from Japan Society for the Promotion of Science (No. 18208023) and the SKYLARK Food Science Institute. 


\section{References}

Abercrombie ED, Keefe KA, Difrischia DS, Zigmond MJ (1989) Differential effect of stress on in vivo dopamine release in striatum, nucleus accumbens, and medial frontal cortex. J Neurochem 52: 1655-1658

Arco AD, Mora F (2001) Dopamine release in the prefrontal cortex during stress is reduced by the local activation of glutamate receptors. Brain Res Bull 56: $125-130$

Asechi M, Tomonaga S, Tachibana T, Han L, Hayamizu K, Denbow DM, Furuse M (2006) Intracerebroventricular injection of L-serine analogs and derivatives induces sedative and hypnotic effects under an acute stressful condition in neonatal chicks. Behav Brain Res 170: 71-77

Bhattacharjee A, Bansal M (2005) Collagen structure the Madras triple helix and the current scenario. IUBUB Life 57: 161-172

Davis JL, Masuoka DT, Gerbrandt LK, Cherkin A (1979) Autoradiographic distribution of L-proline in chicks after intracerebral injection. Physiol Behav 22: 693-695

Delport M, Maas S, Van der merwe SW, Laurens JB (2004) Quantitation of hydroxyproline in bone by gas chromatography-mass spectrometry. J Chromatogr 804: 345-351

Farah Jr JM, Rao TS, Mick SJ, Coyne KE, Iyengar S (1991) N-methyl-D-aspartate treatment increases circulating adrenocrticotropin and luteinizing hormone in the rat. Endocrinology 128: 1875-1880

Feltenstein MW, Lambdin LC, Ganzera M, Ranjith H, Dharmaratne W, Nanayakkara NP (2003a) Anxiolytic properties of Piper methysticum extract samples and fractions in the chick social-separation-stress procedure. Phytother Res 17: 210-216

Feltenstein MW, Lambdin LC, Webb HE, Warnick JE, Khan SI, Khan IA, Acevedo 
ED, Sufka KJ (2003b) Corticosterone response in the chick separation-stress paradigm. Physiol Behav 78: 489-493

Fremeau Jr RT, Caron MG, Blakely RD (1992) Molecular cloning and expression of a high affinity L-proline transporter expressed in putative glutamatergic pathways of rat brain. Neuron 8: 915-926

Gogos JA, Sautha M, Takacs Z, Beck KD, Luine V, Lucas LR, Nadler JV, Karayiorgou M (1999) The gene encoding proline dehydrogenase modulates sensorimotor gating in mice. Nat Genet 21:434-439

Gruss M, Braun K (1996) Distinct activation of monoaminergic pathways in chick brain in relation to auditory imprinting and stressful situations: a microdialysis study. Neuroscience 76: 891-899

Gruss M, Bredenkotter M, Braun K (1999) N-methyl-D-aspartate receptor-mediated modulation of monoaminergic metabolites and amino acids in the chicks forebrain: an in vivo microdialysis and electrophysiology study. J Neurobiol 40: $116-135$

Halpain S, Wieczorek CM, Rainbow TC (1984) Localization of L-glutamate receptors in rat brain by quantitative autoradiography. J Neurosci 4: $2247-2258$

Hamasu K, Haraguchi T, Kabuki Y, Adachi N, Tomonaga S, Sato H, Denbow D.M., Furuse M (2009) L-Proline is a sedative regulator of acute stress in the brain of neonatal chicks. Amino Acids (in press)

Harvey R, Depner U, Wassle H, Ahmadi S, Heindl C, Reinold H, Smart T, Harvey K, Schutz B, Akbari O, Zimmer A, Poisbeau P, Welzl H, Wolfer H, Betz H, Zeilhofer U, Muller U (2004) Gly Ralpha3: an essential target for spinal PGE2-mediated inflammatory pain sensitization. Science 304: 884-888

Henzi V, Reichling DB, Helm SW, Macdermott AB (1992) L-Proline activates glutamate and glycine receptors in cultured rat dorsal horn neurons. Mol 
Pharmacol 41: 793-801

Jazova D, Tokarev D, Rusnak M (1995) Endogenous excitatory amino acids are involved in stress-induced adrenocorticotropin and catecholamine release. Neuroendocrinology 62: 326-332

Joanny P, Steinberg J, Oliver C, Grino M (1997) Glutamate and $\mathrm{N}$-methyl-D-aspartate stimulate rat hypothalamic corticotropin-releasing factor secretion in vitro. J Neuroendocrinology 9: 93-97

Koutoku T, Takahashi H, Tomonaga S, Oikawa D, Saito S, Tachibana T, Han L, Hayamizu K, Denbow DM, Furuse M (2005) Central administration of phosphatidylserine attenuates isolation stress-induced behavior in chicks. Neurochem Int 47: 183-189

Lindstrom P, Ohlsson L (1992) Effect of N-methyl-D,L-aspartate on isolated rat somatotrophs. Endocrinology 131: 1903-1907

Lopez-Corcuera B, Geerlings A, Aragon C (2001) Glycine neurotransmitter transporters: an update. Mol Membr Biol 18: 13-20

Mahesh VB, Zamorano P, Sevilla LD, Lewis D, Brann DV (1999) Characterization of ionotropic glutamate receptors in rat hypothalamus, pituitary and immortalized gonadotropin-releasing hormone (GnRH) neurons (GT1-7 cells). Neuroendocrinology 69: 397-407

Messia MC, Falco TD, Panfili G, Marconi E (2008) Rapid determination of collagen in meat-based foods by microwave hydrolysis of proteins and HPAEC-PAD analysis of 4-hydroxyproline. Meat Sci (in press)

Ortiz JG, Cordero ML, Rosado A (1996) Proline-glutamate interactions in the CNS. Prog Neuro-Psychoph 21: 141-152

Panksepp J, Bean NJ, Bishop P, Vilberg T, Sahley TL (1980) Opioid blockade and social comfort in chicks. Pharmacol Biochem Behav 13: 673-683

Powell J (2006) Skin physiology. Women Health Med 3:130-133 
Renick SE, Kleven DT, Chan J, Stenius K, Milner TA, Pickel VM, Fremeau Jr RT (1999) The mammalian brain high-affinity L-proline transporter is enriched preferentially in synaptic vesicles in a subpopulation of excitatory nerve terminals in rat forebrain. J Neurosci 19: 21-33

Sahley TL, Panksepp J, Zolovick AJ (1981) Cholinergic modulation of separation distress in the domestic chick. Eur J Pharmacol 72: 261-264

Snyder SH, Young AB, Bennett JP, Mulder AH (1973) Synaptic biochemistry of amino acids. Fed Proc 32: 2039-2047

Takagi T, Ando R, Ohgushi A, Yamashita T, Dobashi E, Hussain-Yusuf H, Onodera R, Bungo T, Sato H, Furuse M (2001) Intracerebroventricular injection of pipecolic acid inhibits food intake and induces sleeping-like behaviors in the neonatal chick. Neurosci Lett 310: 97-100

Tanida M, Katsuyama M, Sakatani K (2007) Relation between mental stress-induced prefrontal cortex activity and skin conditions: a near-infrared spectroscopy study. Brain Res 1184: 210-216

Uitto J (1971) Collagen biosynthesis in human skin. Ann clin res 3: 250-258

Van Luijtelaar ELJM, van der Grinten CPM, Blokhuis HJ, Coenen AML (1987) Sleep in the domestic hen (Gallus domesticus). Physiol Behav 41: 409-414

Yoneda S, Roberts E (1982) A new synaptosomal biosynthetic pathway of proline from ornithine and its negative feedback inhibition by proline. Brain Res 239: $479-488$ 


\section{Legend of figure}

Fig. 1. Effect of i.c.v. injection of L-proline, D-proline, and trans-4-hydroxy-L-proline (Hydroxyl-proline) on distress vocalizations during 10 min isolation in 4- or 5-day-old layer chicks. Results are expressed as means \pm SEM. The number of chicks used in each group was five. Groups with different superscripts are significantly different $(P<0.05)$.

Fig. 2. Effect of i.c.v. injection of L-proline, D-proline, and trans-4-hydroxy-L-proline (Hydroxyl-proline) on plasma corticosterone concentration after isolation stress for $10 \mathrm{~min}$ in 4 - or 5-day-old layer chicks. Results are expressed as means \pm SEM. The number of chicks used in each group was as follows: control, five; L-proline, five; D-proline, five; trans-4-hydroxy-L-proline, five; intact, four. Groups with different superscripts are significantly different $(P<0.05)$.

Fig. 3. Effect of i.c.v. injection of either $2.99 \mathrm{nmol}$ of strychnine, $0.50 \mu \mathrm{mol}$ of L-proline, or strychnine plus L-proline on distress vocalizations during $10 \mathrm{~min}$ isolation in 4- or 5-day-old layer chicks. Results are expressed as means \pm SEM. The number of chicks used in each group was as follows: control, five; strychnine, six; L-proline, six; strychnine+L-proline, six.

Fig. 4. Effect of i.c.v. injection of either 2.99 nmol of strychnine, $0.50 \mu \mathrm{mol}$ of D-proline, or strychnine plus D-proline on distress vocalizations during $10 \mathrm{~min}$ isolation in 4- or 5-day-old layer chicks. Results are expressed as means \pm SEM. The number of chicks used in each group was as follows: control, seven; strychnine, six; D-proline, five; strychnine+D-proline, eight. 
Fig. 5. Effect of i.c.v. injection of either $0.50 \mathrm{nmol}$ of (+)-MK-801, $0.50 \mu \mathrm{mol}$ of L-proline, or strychnine plus L-proline on distress vocalizations during 10 min isolation in 4- or 5-day-old layer chicks. Results are expressed as means \pm SEM. The number of chicks used in each group was as follows: control, seven; (+)-MK-801, eight; L-proline, seven; (+)-MK-801+L-proline, eight. Groups with different superscripts are significantly different $(P<0.05)$. 
Fig. 1

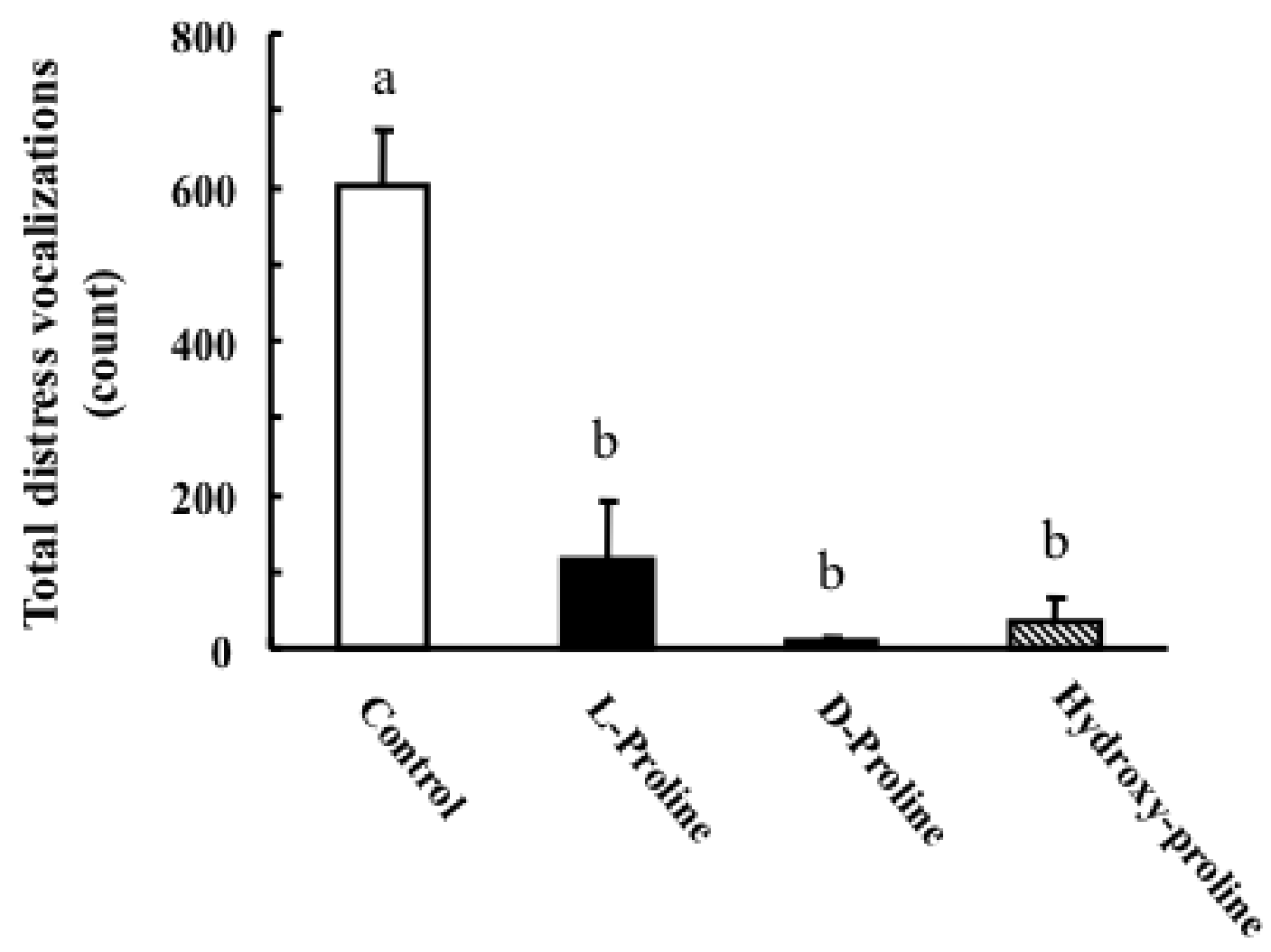


Fig. 2

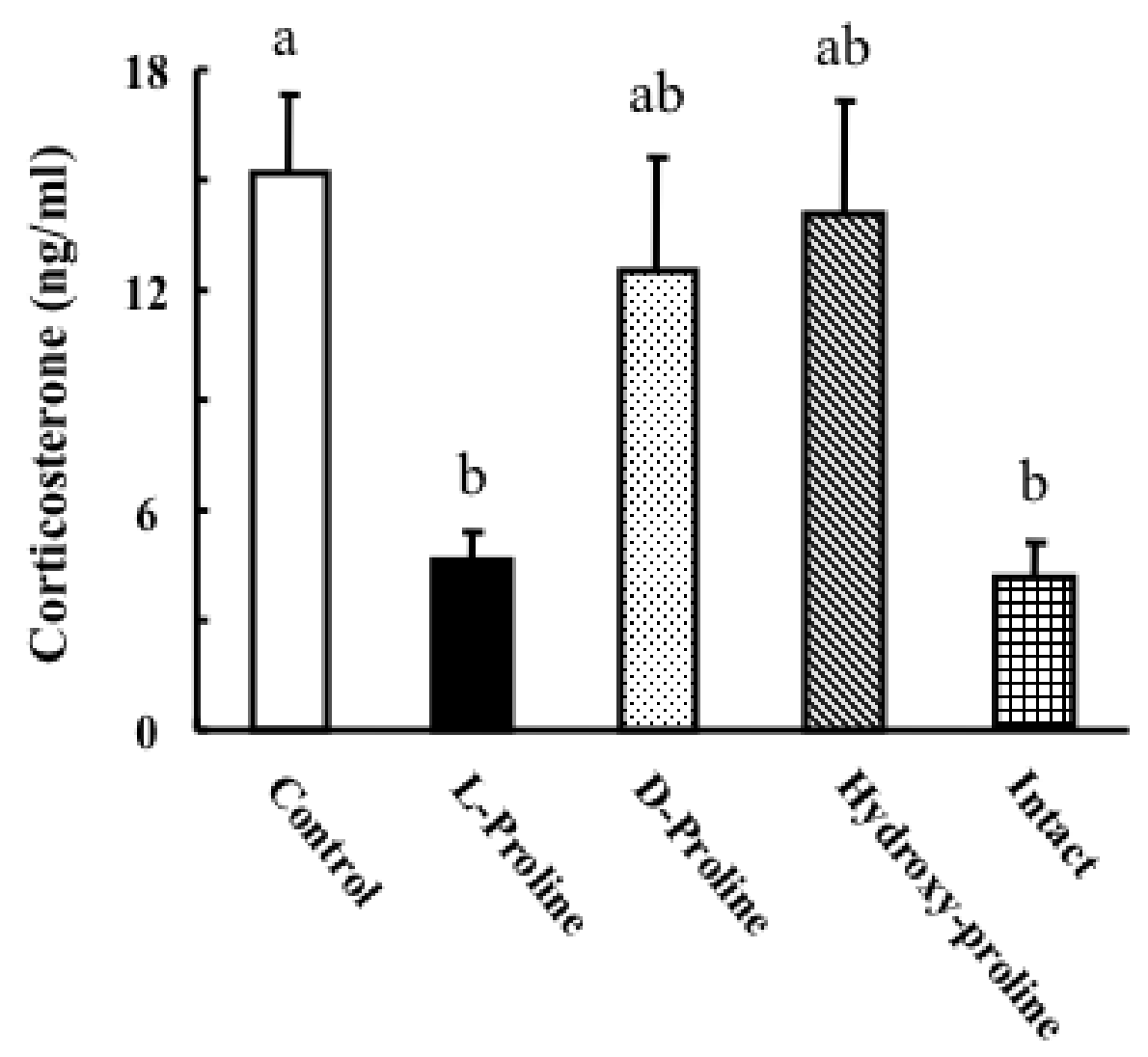


Fig. 3

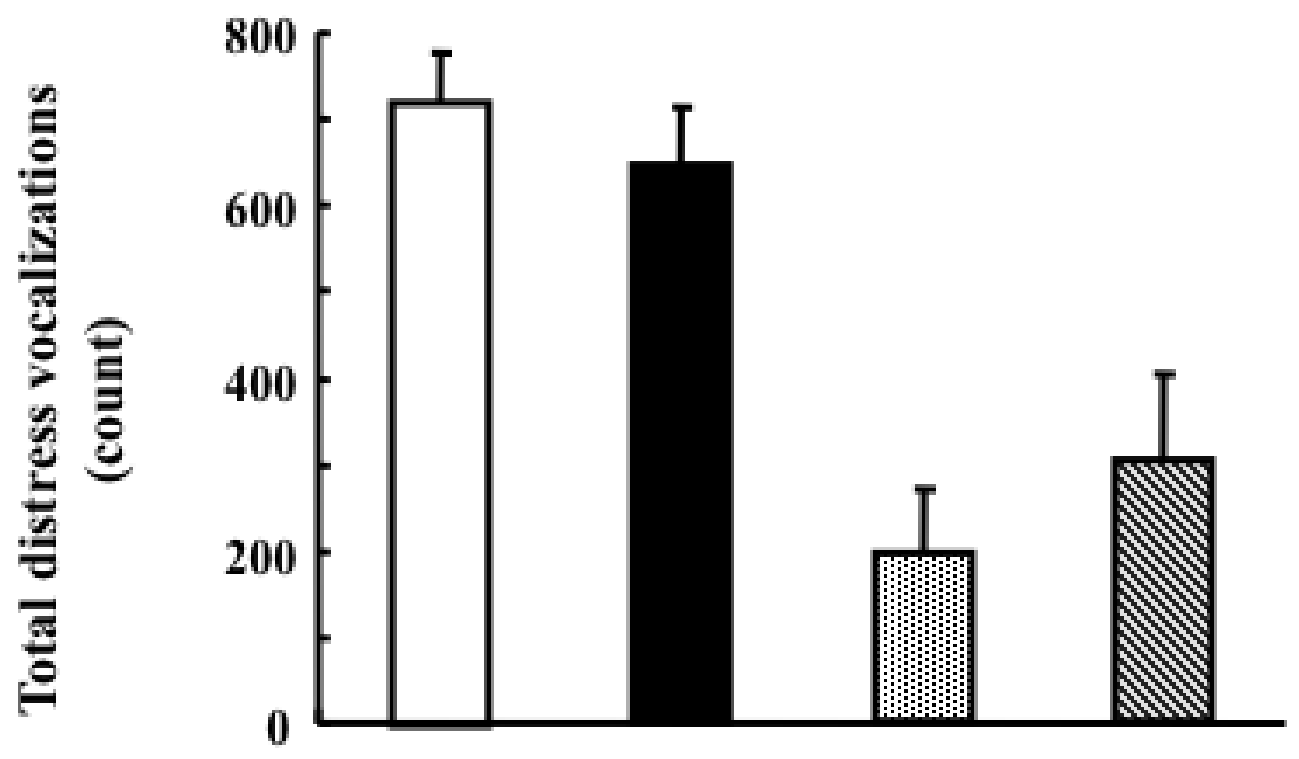

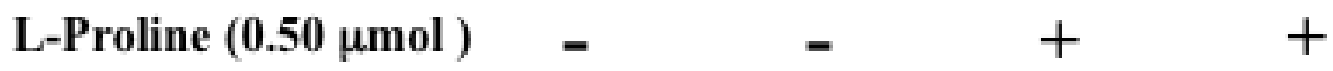

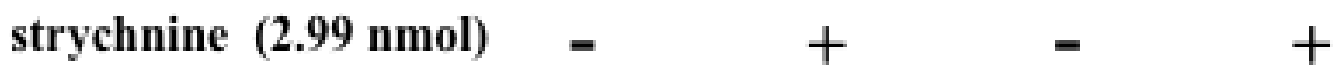


Fig. 4

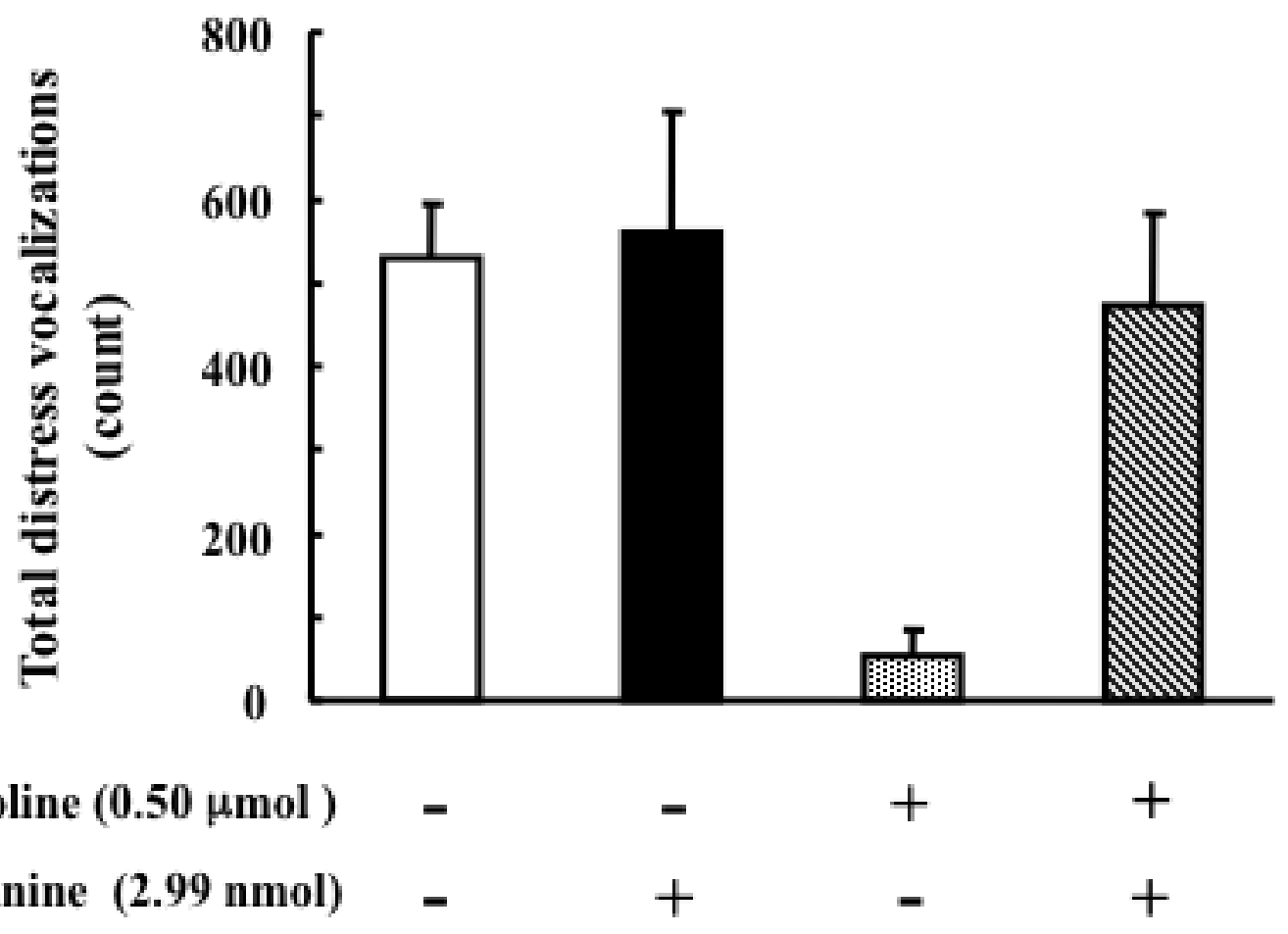


Fig. 5

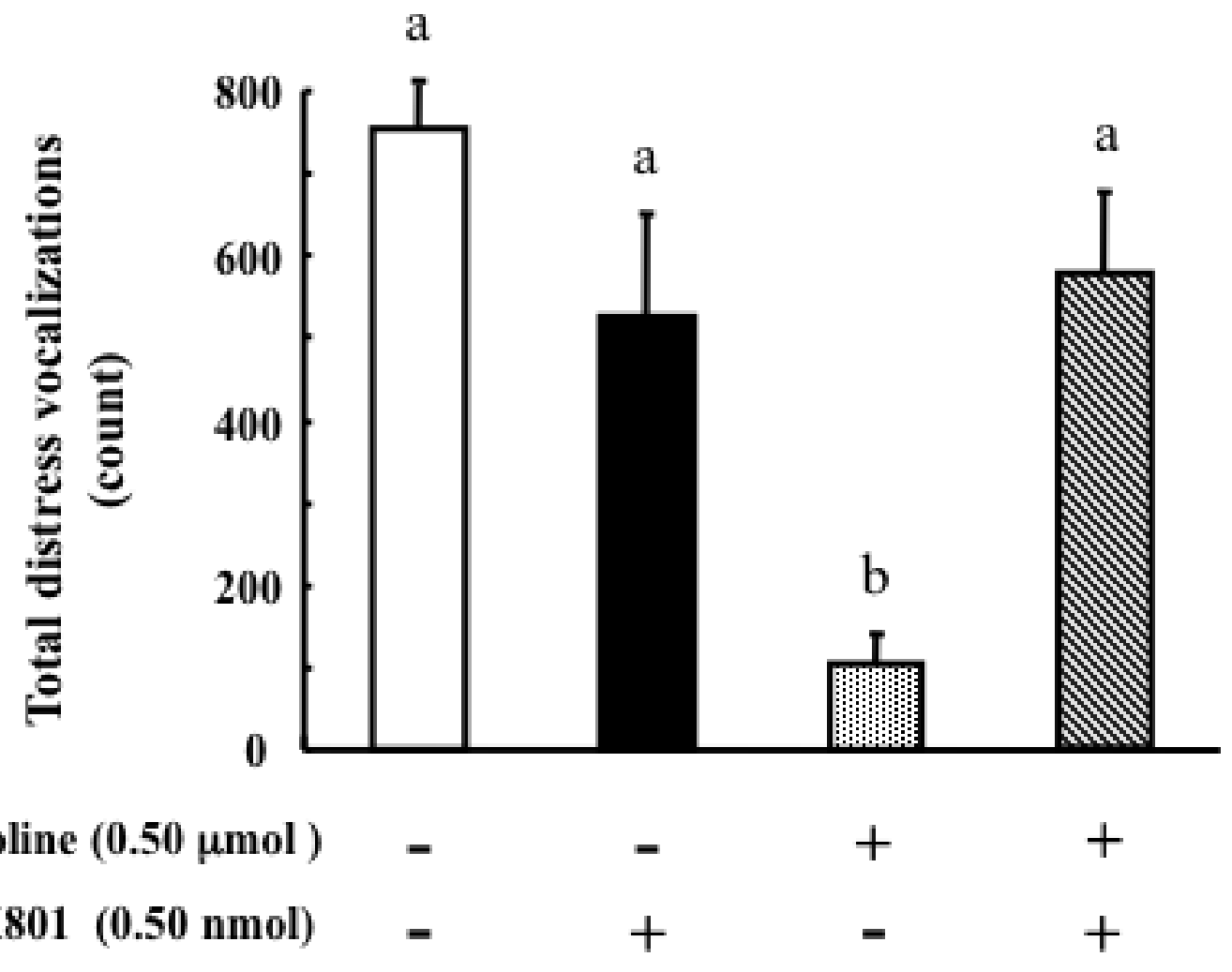


Table 1. Influence of i.c.v. injections of saline, L-proline, D-proline, or trans-4-hydroxy-L-proline on various behavioral categories of chicks 10 min post-injection

\begin{tabular}{|c|c|c|c|c|}
\hline & Control & L-Proline & D-Proline & Trans-4-hydroxy-L-proline \\
\hline Active wakefulness & $474 \pm 39^{\mathrm{a}}$ & $64 \pm 41^{\mathrm{b}}$ & $7 \pm 7^{\mathrm{b}}$ & $45 \pm 39^{b}$ \\
\hline $\begin{array}{l}\text { Standing/sitting motionless } \\
\text { with eyes open }\end{array}$ & $126 \pm 39$ & $152 \pm 25$ & $155 \pm 52$ & $158 \pm 23$ \\
\hline $\begin{array}{l}\text { Standing motionless with } \\
\text { eyes closed }\end{array}$ & $0 \pm 0$ & $0 \pm 0$ & $25 \pm 25$ & $0 \pm 0$ \\
\hline $\begin{array}{l}\text { Sitting motionless with head } \\
\text { drooped (sleeping posture) }\end{array}$ & $0 \pm 0^{\mathrm{a}}$ & $384 \pm 37^{\mathrm{b}}$ & $413 \pm 78^{b}$ & $397 \pm 38^{b}$ \\
\hline Total (second) & 600 & 600 & 600 & 600 \\
\hline
\end{tabular}

Values are means \pm SEM in seconds. The number of chicks used in each group was five. Groups with different letters are significantly different $(P<0.05)$. 
Table 2. Influence of i.c.v. injections of strychnine and L-proline on various behavioral categories of chicks 10 min post-injection

\begin{tabular}{|c|c|c|c|c|c|c|c|}
\hline \multirow[b]{2}{*}{ Strychnine } & \multicolumn{2}{|c|}{ Saline } & \multicolumn{2}{|c|}{ L-Proline } & \multicolumn{3}{|c|}{$P$} \\
\hline & - & + & - & + & L-Proline & Strychnine & $\begin{array}{l}\text { L-Proline } \times \\
\text { Strychnine }\end{array}$ \\
\hline Active wakefulness & $508 \pm 42^{\mathrm{a}}$ & $521 \pm 24^{\mathrm{a}}$ & $185 \pm 63^{b}$ & $240 \pm 83^{b}$ & $<0.001$ & NS & NS \\
\hline $\begin{array}{l}\text { Standing/sitting motionless } \\
\text { with eyes open }\end{array}$ & $89 \pm 39$ & $74 \pm 21$ & $170 \pm 55$ & $130 \pm 23$ & NS & NS & NS \\
\hline $\begin{array}{l}\text { Standing motionless with } \\
\text { eyes closed }\end{array}$ & $3 \pm 3$ & $5 \pm 5$ & $132 \pm 60$ & $109 \pm 83$ & $<0.05$ & NS & NS \\
\hline $\begin{array}{l}\text { Sitting motionless with head } \\
\text { drooped (sleeping posture) }\end{array}$ & $0 \pm 0$ & $0 \pm 0$ & $113 \pm 67$ & $121 \pm 68$ & $<0.05$ & NS & NS \\
\hline Total (second) & 600 & 600 & 600 & 600 & & & \\
\hline
\end{tabular}

Values are means \pm SEM in seconds. The numbers of chicks used were: saline, five; strychnine, six; L-proline, six; L-proline +

strychnine, six. NS, not significant. Groups with different letters are significantly different $(P<0.05)$. 
Table 3. Influence of i.c.v. injections of strychnine and D-proline on various behavioral categories of chicks 10 min post-injection

\begin{tabular}{|c|c|c|c|c|c|c|c|}
\hline \multirow[b]{2}{*}{ Strychnine } & \multicolumn{2}{|c|}{ Saline } & \multicolumn{2}{|c|}{ D-Proline } & \multicolumn{3}{|c|}{$P$} \\
\hline & - & + & - & + & D-Proline & Strychnine & $\begin{array}{l}\text { D-Proline } \times \\
\text { Strychnine }\end{array}$ \\
\hline Active wakefulness & $434 \pm 48^{\mathrm{a}}$ & $443 \pm 86^{\mathrm{a}}$ & $71 \pm 45^{b}$ & $397 \pm 51^{\mathrm{a}}$ & $<0.01$ & $<0.05$ & $<0.05$ \\
\hline $\begin{array}{l}\text { Standing/sitting motionless } \\
\text { with eyes open }\end{array}$ & $127 \pm 29$ & $76 \pm 36$ & $166 \pm 39$ & $102 \pm 32$ & NS & NS & NS \\
\hline $\begin{array}{l}\text { Standing motionless with } \\
\text { eyes closed }\end{array}$ & $39 \pm 22$ & $43 \pm 28$ & $10 \pm 10$ & $64 \pm 34$ & NS & NS & NS \\
\hline $\begin{array}{l}\text { Sitting motionless with head } \\
\text { drooped (sleeping posture) }\end{array}$ & $0 \pm 0^{\mathrm{a}}$ & $38 \pm 24^{\mathrm{a}}$ & $353 \pm 90^{\mathrm{b}}$ & $37 \pm 28^{\mathrm{a}}$ & $<0.001$ & $<0.01$ & $<0.001$ \\
\hline Total (second) & 600 & 600 & 600 & 600 & & & \\
\hline
\end{tabular}

Values are means \pm SEM in seconds. The numbers of chicks used were: saline, seven; strychnine, six; D-proline, five; D-proline +

strychnine, eight. NS, not significant. Groups with different letters are significantly different $(P<0.05)$. 
Table 4. Influence of i.c.v. injections of MK801 and L-proline on various behavioral categories of chicks 10 min post-injection

\begin{tabular}{|c|c|c|c|c|c|c|c|}
\hline \multirow[b]{2}{*}{ MK801 } & \multicolumn{2}{|c|}{ Saline } & \multicolumn{2}{|c|}{ L-Proline } & \multicolumn{3}{|c|}{$P$} \\
\hline & - & + & - & + & L-Proline & MK801 & $\begin{array}{l}\text { L-Proline } \times \\
\text { MK801 }\end{array}$ \\
\hline Active wakefulness & $512 \pm 46^{\mathrm{a}}$ & $343 \pm 66^{\mathrm{a}}$ & $110 \pm 38^{\mathrm{b}}$ & $407 \pm 52^{\mathrm{a}}$ & $<0.01$ & $\mathrm{NS}$ & $<0.001$ \\
\hline $\begin{array}{l}\text { Standing/sitting motionless } \\
\text { with eyes open }\end{array}$ & $43 \pm 15^{\mathrm{a}}$ & $193 \pm 41^{b}$ & $189 \pm 31^{b}$ & $157 \pm 39^{\mathrm{ab}}$ & NS & NS & $<0.05$ \\
\hline $\begin{array}{l}\text { Standing motionless with } \\
\text { eyes closed }\end{array}$ & $40 \pm 27$ & $34 \pm 24$ & $77 \pm 25$ & $36 \pm 18$ & NS & NS & NS \\
\hline $\begin{array}{l}\text { Sitting motionless with head } \\
\text { drooped (sleeping posture) }\end{array}$ & $5 \pm 5^{\mathrm{a}}$ & $30 \pm 17^{\mathrm{a}}$ & $224 \pm 75^{b}$ & $0 \pm 0^{\mathrm{a}}$ & $<0.05$ & $<0.05$ & $<0.01$ \\
\hline Total (second) & 600 & 600 & 600 & 600 & & & \\
\hline
\end{tabular}

Values are means \pm SEM in seconds. The numbers of chicks used were: saline, seven; MK801, eight; L-proline, seven; L-proline +

MK801, eight. NS, not significant. Groups with different letters are significantly different $(P<0.05)$. 